\title{
77
}

\section{Concept, Realisation, and Evaluation of SEMIK}

\author{
Jan Hense, Heinz Mandl, Katja Kruppa and Cornelia Gräsel \\ Education and Educational Psychology, Ludwigs-Maximilian-Universität München, Leopoldstr. \\ 13, 80802 München, Germany \\ hense@emp.paed.uni-muenchen.de
}

Keywords: integration of ICT, national programme, evaluation, catalyst for adaption/changes

\begin{abstract}
The programme SEMIK comprises 25 different projects in all parts of Germany. Its main goals are: implementing new media in all grades and kinds of schools in a sustainable way, applying innovative methods of teaching and learning, promoting students' media literacy, and advancing school development. To ensure the quality of the programme and to assess its outcomes, measures of formative, summative, and self-evaluation have been combined. Early results of the evaluation process are reported and general consequences for the sustainable implementation of new media and ICT in schools are discussed. It is argued that a systemic perspective and provision of new concepts for learning and teaching are mandatory for the success of similar programmes.
\end{abstract}

\section{THE PROGRAMME SEMIK}

New media and the closely interrelated possibilities of information and communication technologies have a growing impact on our professional and private everyday lives. One of the central tasks of today's schools therefore is to enable students to use these new techniques in an active and at the same time reflective way. The national programme 'Systematic Integration of Media, Information and Communication Technologies in Teaching and Learning' (SEMIK), which is jointly funded by the German government and the 16 federal states, aims at contributing a solution to this task. 
This paper will describe the concept and realisation of the programme, illustrate the function of its scientific consultation, evaluation and selfevaluation, report first results, and discuss necessary consequences.

\subsection{Goals of the programme}

The central guiding principles of the programme are built around a conceptual framework (Mandl, Reinmann-Rothmeier and Gräsel 1998): A superior goal of education is the necessity for lifelong learning in a knowledge society which gives rise to additional demands for their members. It is mandatory to create conditions for this kind of learning in schools. The didactical guiding principle of problem oriented learning, which is inspired by moderate constructivist models of learning research, is appropriate for these needs (e.g. Cognition and Technology Group at Vanderbilt 1997). Additionally, it is believed that in the end a change of the learning culture in schools is needed to bring this guiding principle into action.

The main goal of SEMIK and each of its projects is to implement media in all grades and all kinds of schools in a sustainable way. The main focus is on projects using new media and information and communication techniques (ICT). New media are to be embedded in processes of learning and teaching, and are to serve the realisation of innovative concepts of teaching. The main emphasis is on problem oriented, self-directed, and cooperative learning. Reception as well as production of media is meant to foster students' media literacy, i.e. reflection and responsibility in using media. Processes of school development are a precondition for sustainable progress, for without changing or at least considering the framework of schools, changing of schools and teaching beyond the duration of projects seems unachievable.

\subsection{Scientific consultation}

The role of the central scientific consultation of SEMIK is to support projects in fulfilling the intended goals. Besides evaluation, which is to be described in a section of its own, this involves the following tasks:

1. Scientific consultation and support for the projects. This includes consulting projects in translating the programme's principles into action, supplying theoretical and practical input, consulting projects in commissioning additional scientific services, and advising the programme coordination in commissioning additional external services.

2. Promotion of cooperation and creation of networks. Necessary steps to enable synergy effects among the different projects include the installation of a central infrastructure for communication and cooperation, 
organisation of central workshops and encouragement of cooperation between projects and with external partners.

3. Documentation and reporting. To set out the results of the programme in writing in a systematic way, guidelines for documentations and reports had to be devised.

\section{REALISATION AND MAIN FOCUSES OF THE PROGRAMME}

The programme SEMIK has started in September 1998 and will last for five years. It comprises 25 different projects in all of the 16 federal German states. Each of the 25 projects is concerned with one or more of five main focuses, which will be described in detail.

\subsection{Development of new concepts of teaching}

The new media offer a huge potential for applying new instructional methods, for the use of new media should never be a purpose of its own. Much more important than supplying technical equipment is to answer the question which problems are to be solved better with new media than with conventional means. Therefore we need concepts that reveal how the potential for innovation inherent to new media can be used to support new forms of teaching and learning. Traditional structures of teaching often restrict or even inhibit constructivist activities, self-regulation, reflection, and cooperation of learners. Therefore new media should be used to create learning environments following the principle of problem orientation, thus favouring a balance between instruction and construction (Gräsel 1997).

\subsection{Teacher education and further education}

Teachers have a key role in changing education by the use of new media. Teachers have to know how to use new media as a tool in lessons, they have to be able to judge the impact of new media on students, they have to look out for equal opportunities in accessing new media, and they have to use new media for their own learning in- and outside of official further education. Since only some of today's teachers are able to meet these demands, this cannot be confined to teacher education, but must include further education. It seems most appropriate to enhance traditional further education by school internal training. The possibility of implementing new 
ideas and knowledge more directly than in traditional seminars prevents the production of 'inert knowledge' (Renkl 1996).

\subsection{School development}

Systematic integration of new media in schools is expected to cause far reaching structural changes. On the other hand, to attain sustainability it depends on a systematic change inside of schools. This refers to flexibility in temporal, spatial, and subject-related structures, as well as to personnel and budget planning. School itself has to become a learning organisation. One of the central measures to set off this process is to develop school programmes and profiles that are tailored to the potential and context of a specific school.

\subsection{Development of technical tools}

Availability and access to media have often been found to be a particular weakness for using the potentials of ICT in an optimal way. Therefore development and provision of technical tools has become another main focus of the programme. This includes technical equipment (hardware, software, networks) as a mandatory precondition, tools for editing and presentation of contents, tools for interactive cooperation and communication, and finally access to digitised media for learning and teaching. Since plenty of tools are already available, it is more important to work out and show ways of making these more accessible to learners and teachers, and how they are to be integrated into everyday school.

\subsection{Curricula development}

Learning and teaching are dependent on content. It is expected that significant changes will have to be made in curricula to adequately use the potential for innovation inherent to new media. The subject, defining a topical and temporal systematic and possessing its own pedagogicaldidactical logic, has a central role in our schools. Two tasks for curricula development evolve. First, the strict boundaries between subjects have to be torn down to enable interdisciplinary learning. The subsequent emphasis on complex and authentic problems enforces the reduction of the contents of curricula (Cognition and Technology Group at Vanderbilt 1997). Second, we need curricular concepts that coordinate the didactical use of new media with the requirements of specific subjects. 


\section{EVALUATION}

Evaluation is taking place on the levels of single schools, on the level of each single project, and on the level of the overall programme. The evaluation of SEMIK is aimed at two major goals.

1. Ensuring quality by formative evaluation. By taking accompanying measures of evaluation, improvements are planned to be initiated while the programme is still running. This is accomplished by giving feedback to the projects on the results of the evaluation, by offering support on problematic areas, and by identifying best practice models among the participating projects.

2. Assessing success by summative evaluation. By reviewing the outcomes of the programme in its end, its achievements are to be documented for its employers and the interested public.

\subsection{Dimensions of evaluation}

The evaluation of SEMIK is concerned with four central topics, which are to be described in detail in the following sections.

\subsubsection{Potential for innovation inherent to the systematic use of new media and ICT}

The term 'potential for innovation' includes all questions concerning the degree to which change in schools is supported by the use of media. Three areas of interest have been found to be particularly central in regard to the potential for innovation of the use of media. Each area is given with an exemplary question.

1. Learning culture; e.g. what kinds of teaching and learning methods are most effective in integrating new media and ICT?

2. School development; e.g. which technical and organisational conditions promote or inhibit the course of the project?

3. Competencies and learning success; e.g. do uses of new media enable learning outcomes that would not have been possible or as effective without it?

\subsubsection{Cooperation within the programme and with external partners}

One of the central goals of the programme is to encourage the creation of networks between projects. Therefore this is also a question of interest for evaluation. 
- Do projects cooperate with other projects within or outside of the programme or with external partners?

- Which factors do promote or inhibit cooperation of projects?

- Have there been steps to improve possibilities of communication? Which role did ICT play?

\subsubsection{Transferability of results}

Even while the projects are still running, one can observe to what degree results and products are apt to be transferred to other projects. The following questions are central.

- Have there been steps to make the results of the projects available and usable for other schools, projects, or federal states?

- Are conditions for success of a project identifiable that might be of interest for others?

- Are the results usable in different frames of conditions?

\subsubsection{Sustainability of effects}

An important criterion of success for projects concerned with promoting innovation is the sustainability of changes that have been initiated. The following questions are of interest.

- Which media are used? Which is the role of ICT?

- Which changes in structure and which measures of school development ensure the broad use of media and ICT in school even after the project has ended?

- Which steps have been taken to use the results of the project after the termination of funding?

\subsection{The process of evaluation}

A broad spectrum of different instruments and measures has been developed, tested, and partly revised to evaluate the SEMIK projects.

Questionnaires for students and teachers exist in online and paper-pencil versions. The main evaluative phase of SEMIK gathers data on participants' views on topics such as usage, acceptance, motivation, and attitudes concerning new media and new concepts of teaching, changes in learning and teaching, and context conditions.

Structured interviews with participants have been taking place since shortly after the beginning of the programme. The data has been summarised and commented on, to be able to give projects appropriate feedback on their progress. 
Schemes for the documentation of lessons/trainings and schemes for participant observation of lessons are used to gain insight into what is actually happening in classrooms. Data collected by using them adds to the picture gained by questionnaires and interviews.

\subsection{Self-evaluation}

The major goal of self-evaluation in SEMIK is to enhance the quality of the participating projects' work on a personal level. Teachers use the results of self-evaluation to reflect on their professional behaviour and improve it subsequently (Buhren, Killus and Müller 1998). The results of those four projects that take intensified measures of self-evaluation are made available for the whole programme by delivering reports of their experiences. All measures of self-evaluation are closely linked with the external evaluation.

Instruments of self-evaluation have been developed in close cooperation with participating teachers. This included clarifying teachers' specific goals, finding indicators for the achievement of these goals, devising instruments to measure these goals, testing the instruments, and discussing their outcomes. Typical instruments that have been developed this way are pedagogical diaries, guidelines for interviews with students, questionnaires, observation schemes, checklists, and schemes for documentation of lessons.

\section{RESULTS}

Although the SEMIK programme is still far from termination, results from the early phases of the evaluation process are already available. At the moment, their function is on one hand to be used as a means of feedback and correction for the programme, and on the other hand to reveal important consequences for the general introduction of new media in schools.

\subsection{Uses of new media}

New media have been used in a variety of different ways and applications in the context of the individual SEMIK-projects' goals.

1. In regular lessons, e.g. as a tool to present the results of students' assignments or as a means of seeking information.

2. As a medium of communication and cooperation to facilitate exchange in schools and between schools and other institutions.

3. As basis for phases of self-regulated learning. 
4. As subject-matter, e.g. to promote media literacy or method competencies.

\subsection{Innovative concepts of learning and teaching}

Many of the projects have taken significant steps towards a central goal of the SEMIK programme: the realisation and testing of innovative concepts of learning and teaching in school as well as in further training of teachers. Some basic conditions have been identified that determine the success of these innovative concepts: One recurrent obstacle was insufficient technical equipment in some of the projects. So the need for a proper setting was identified as one essential precondition.

Another basic condition concerned the varying need of the programme's participants for further training in topics such as 'innovative concepts of teaching' or 'project management'. Many of the participating projects provided evidence that changing teachers' roles from facilitators of knowledge to moderators of learning processes is a goal not easily reached. Therefore further training dealing with these pedagogic-didactic topics for participating teachers has been a measure applied more often than initially intended. The exchange of best practice models in intra-school trainings proved to be a particularly effective measure.

\subsection{School development}

To realise the systematic implementation of media thoroughly and effectively it is necessary to clearly codify this goal in a school's programme. Those schools and projects that explicitly put down the use of media in their school programmes already show sustainable changes in structure at this moment, since support of most of the school's teachers is thus ensured.

Tendencies like these are not only to be recognised in projects belonging to the programmes' main focus 'school development' but also in other SEMIK-projects. Similar statements can be made for the main focus 'teacher education and further education'. Cooperation within schools' staffs, e g. by team teaching, by mutual support in further training, or by exchange of experiences has been identified as an integral part of processes of school development 


\subsection{Conclusion}

The overall balance that can be struck of the SEMIK programme at the time of writing shows a positive picture. A number of developments have been initiated that implement new media in schools on a pedagogical basis. Nevertheless, it has become clear to what degree the success of this process of implementation depends on certain basic conditions, in particular technical and personal set-up, curricula, and opportunities for further education. Up to now, at least four goals have been reached within the programme:

1. All participants succeeded in enhancing their competencies necessary for the implementation of new media in processes of learning and teaching significantly. This increase in qualification is an important foundation for further efforts.

2. Participants' reluctance concerning the use of new media in education has been reduced in a number of projects. This is an essential condition for the sustainable implementation of new media.

3. Cooperation between teachers has been intensified significantly by participation in the projects.

4. Important effects of synergy have been accomplished by cooperation of projects with each other.

\section{CONSEQUENCES}

At the moment, two basic consequences for the sustainable implementation of new media and ICT in schools seem inevitable when taking into account the experiences made in the programme SEMIK based on the first results of evaluation.

1. The introduction of new media cannot be confined to enriching conventional methods of instruction with new technologies. It rather has to be accompanied by measures on all levels that are relevant for school life. From a systemic point of view, this must include the revision of curricula, the adjustment of teacher education, the promotion of school development, as well as changes in methods of teaching and learning.

2. The introduction of new media depends on supplying new concepts for teaching and learning. Teachers cannot be expected to develop completely new lessons and projects from scratch as an additional effort. To reduce this deficit seems to be an important challenge for future research. 


\section{REFERENCES}

Buhren, C. G., Killus, D. and Müller, S. (1998) Wege und Methoden der Selbstevahuation. Ein praktischer Leitfaden für Schulen. IFS-Verlag, Dortmund.

Cognition and Technology Group at Vanderbilt (1997) The Jasper Project: Lessons in curriculum, instruction, assessment, and professional development. Erlbaum, Mahwah.

Dubs, R. (1998) Qualitätsmanagement für Schulen. Institut für Wirtschaftspädagogik, St. Gallen.

Gräsel, C. (1997) Problemorientiertes Lernen. Strategieanwendung und Gestaltungsmöglichkeiten. Hogrefe, Göttingen.

Mandl, H. and Reinmann-Rothmeier, G. (1995) Unterrichten und Lernumgebungen gestalten. Forschungsbericht Nr. 60, Ludwig-Maximilians-Universität, Institut für Pädagogische Psychologie und Empirische Pädagogik, München.

Mandl, H., Reinmann-Rothmeier, G. and Gräsel, C. (1998) Gutachten zur Vorbereitung des Programms 'Systematische Einbeziehung von Medien, Informations- und Kommunikationstechnologien in Lehr- und Lernprozesse. Bund-Länder-Kommission für Bildungsplanung und Forschungsförderung, Bonn.

Renkl, A. (1996) Träges Wissen: Wenn Erlerntes nicht genutzt wird. Psychologische Rundschau, 47, pp. 78-92.

Resnick, L. B. and Wiliams Hall, M. (1998) Leaming organizations for sustainable education reform. Daedalus, 127 (4), pp. 89-118.

\section{BIOGRAPHY}

Jan Hense is school psychologist and works as scientific employee at the university of Munich, Germany. He is mainly concerned with the scientific consultation and evaluation of SEMIK, and with advising projects in planning and realising their self-evaluation. His research topics include the use of new media in teaching and learning, evaluation of ICT, and selfevaluation.

Heinz Mandl is Professor of Education and Educational Psychology at the Ludwig-Maximilian-University of Munich. His main research areas are knowledge management, acquisition and use of knowledge, net-based knowledge communication, and design of virtual learning environments. $\mathrm{He}$ is initiator of several research programmes of Deutsche Forschungsgemeinschaft (DGF) in Knowledge Psychology, Knowledge and Action, Teaching-Learning-Processes in Initial Business Education, and Netbased Cooperation in Groups. He carried out applied research and development projects with Siemens AG, Andersen Consulting, BMW, and Telekom.

Katja Kruppa is educationist and works as scientific employee at the university of Munich, Germany. She is concerned with the scientific consultation and evaluation of SEMIK. Her research topics include the implementation and use of new media in teaching and learning and evaluation of ICT and problem-based learning environments. 